\title{
Spinozismo y Feminismo: potencia común o de cómo pensar un feminismo spinoziano *
}

\author{
Spinozism and Feminism: common power or on how to think a Spinozian
}

feminism

\author{
Por: Oliva Ríos, Mariela * \\ Universidad Autónoma de la Ciudad de México (UACM) \\ Ciudad de México \\ Email: marielotzin@gmail.com
}

Fecha de recepción: 6/04/2019

Fecha de aprobación: 20/04/2020

DOI: $\underline{10.30972 / n v t .1614345}$

\section{Resumen}

El presente artículo es el resultado de los trabajos presentados en los dos últimos Coloquios Internacionales de Spinoza Américas ${ }^{1}$ y cuyo tema central ha sido el de pensar un feminismo spinoziano. Si partimos de que la filosofía tiene como impronta el someter a crítica discursos y prácticas en el ejercicio de producir pensamiento y que desde ciertas perspectivas filosóficas dicha crítica se plantea en términos radicales que promueven prácticas concretas, sin duda en dicha radicalidad se inscriben tanto el spinozismo como el feminismo, pero ¿qué spinozismo y qué feminismos? ¿Necesita el feminismo del pensamiento spinozista? La respuesta que

\footnotetext{
* El presente trabajo se vincula a los cursos que imparto en la Universidad Autónoma de la Ciudad de México (UACM) tanto de Filosofía feminista como los Seminarios de problemas, textos y autor en torno a la actualidad del pensamiento de Spinoza y el spinozismo; así mismo forma parte de un proyecto de investigación que combina el trabajo teórico como la realización de talleres que permitan pensar un feminismo spinoziano desde América Latina.

* Profesora e investigadora de la Academia de Filosofía e Historia de las Ideas y corresponsable del grupo de investigación Cuerpo y Subjetividad de la Universidad Autónoma de la Ciudad de México (UACM). Maestra en filosofía y licenciada en pedagogía por la Universidad Nacional Autónoma de México (UNAM).

${ }^{1}$ XV Coloquio Internacional Spinoza, El Spinozismo como forma de vida, realizado en Córdoba, Argentina, diciembre 2018 y el XVI Coloquio Internacional Spinoza Américas, Spinoza, Filosofia \& Liberdade, realizado en Rio de Janeiro, Brasil, diciembre 2019.
} 
propongo reflexionar se encuentra en las derivas teórico-prácticas cuya lectura ética y política sostienen un materialismo, es decir, a partir de la noción de potencia común, analizo el entrecruzamiento del spinozismo y el feminismo para pensar un feminismo spinoziano que encuentra en el deseo de vida, en la libertad y la vida afectiva esa potencia común. El debate parte entonces, de algunas de las categorías centrales que enmarcan el horizonte de pensamiento de Spinoza en su ya largo proceso de construcción crítica de un spinozismo latinoamericano; entre ellas el cuerpo, la afectividad, el deseo, esto es los cuerpos políticos, la producción de afectos, y el deseo de lo común. ¿Qué implica políticamente la producción de afectos? ¿Qué afectos y qué cuerpos? La libertad y la vida afectiva implican la producción de afectos, de cuerpos políticos que enuncian formas de estar y de resistir. Mi intención con este trabajo es pensar formas de vida afectiva que nos permitan la búsqueda y creación colectiva de afectos en una apuesta por la vida frente a las violencias estructurales de un sistema patriarcal, capitalista, colonial y racista.

Palabras clave: Spinozismo, feminismo, potencia común, libertad, vida afectiva.

\section{Abstract}

The article is the result of work that has been presented during the two most recent International Colloquiums on Spinoza and the Americas in which the central subject has been Spinozian feminism. If we start by establishing that philosophy's purpose is the critique of discourses and practices taking place in the exercise of producing thought and thus coming from certain philosophical perspectives, that critique is posed in radical terms and geared towards concrete practices, then both Spinozism and feminism are within that register of radicality. The question is which Spinozism and which feminism? Is feminism in need of Spinozian thought? The answer I propose to reflect on is found in the theoretical-practical margins, whose ethical and political reading support a materialism; that is to say, from the notion of common potency, I analyse the crossing of Spinozism and feminism to bring about a Spinozian feminism that finds that common power (potency) in that striving desire for freedom 
and affective life. The debate lies then in some main categories that frame the skyline of Spinoza's thought within the critical construction of the Latin American Spinozism; amongst them are the body, affectivity, desire; that is, political bodies, the production of affects, and the desire of the common. What is the political implication in the production of affections? What affections and which bodies? Freedom and affective life involves the production of affections, of political bodies that enunciate ways of being and resisting. My intention with this work is to think of life-affirming ways that enable the collective search and creation of affections in the face of the structural violence brought by the patriarchal, capitalist, colonial and racist system.

Keywords: Spinozism, feminism, common power, freedom, affective life.

\section{Cómo citar este artículo:}

APA: Oliva Ríos, M. (2020). Spinozismo y Feminismo: potencia común o de cómo pensar un feminismo spinoziano. Nuevo Itinerario, 16 (1), 51-74. Recuperado de: (agregar dirección web)

El pensamiento es un conjunto de fuerzas que se resiste a la muerte. Si pensar es resistir, filosofía, política, crítica y clínica son un mismo movimiento. Lo esencial del pensar no está en el pensamiento sino afuera, en lo que fuerza a pensar.

Gilles Deleuze

\section{Introducción}

¿Qué significa luchar por una altísima existencia? ${ }^{2}$ Nos encontramos en un momento donde lo central es sentipensar la vida frente a la lógica global de una biopolítica de selección de la vida. Sabemos que la vida no transita exclusivamente por el acontecer humano, sin embargo, en su acontecer humano deviene un actuar ético que se expresa en la acción y tal acción no es otra cosa que un estar siendo actualidad política de un conjunto de deseos. Pensemos, por ejemplo, en la afirmación que hace Mbembe (2020) de que "el sistema capitalista se basa en la distribución desigual de la

\footnotetext{
${ }^{2}$ Zuleta (2017). Podemos decir como Fausto: “También esta noche, Tierra, permaneciste firme. Y ahora renaces de nuevo a mi alrededor. Y alientas otra vez en mí la aspiración de luchar sin descanso por una altísima existencia"
} 
oportunidad de vivir y morir", o como escribe Zuleta (2017) "que nuestra desgracia no está tanto en la frustración de nuestros deseos como en la forma misma de desear", o en el reclamo de la lucha de las mujeres que gritan masivamente en las urbes del mundo ¡Vivas Nos Queremos! En esa trama, los debates históricos que la filosofía ha puesto en juego se nos presentan como ausencias, como crisis, como envío de promesas o de profecías auto cumplidas, horizontes apocalípticos, el nihilismo y el sentimiento de la tragedia; pero algo irrumpe, algo inesperado, un desvío, lo abierto del horizonte crítico, la lucha, la memoria, el lugar de la fisura de las oposiciones, de la cicatriz, del encuentro, entonces el filosofar se nos presenta situado y contingente, en medio de y con otros.

Decimos que la filosofía tiene como impronta el someter a crítica discursos y prácticas en el ejercicio de producir pensamiento. En ese sentido, la apuesta crítica no pasa exclusivamente por la enunciación teórica de parámetros de verdad o de certezas, sino por el ejercicio de radicalizar las prácticas, por el afanoso deseo de transformar aquello que parece inamovible. Ahí, la filosofía se plantea como la práctica radical de la crítica, como la apuesta por cuestionar creencias, doctrinas o cualquier superstición ${ }^{3}$ que obstaculice el deseo y la libertad de pensar. En tal deriva, sostenemos que el filosofar que enuncian tanto el spinozismo como algunos feminismos, en su expresión materialista y mediante sus cruces, pasa por la inscripción de la radicalidad de la crítica y su implicación práctica, esto es, por pensar el entendimiento de lo común como práctica colectiva de un deseo de vida contra las violencias hetero-patriarcales, capitalistas, coloniales y racistas.

Pensar los entrecruzamientos conceptuales ${ }^{4}$ del spinozismo y el feminismo significa reflexionar el sentido ético político de aquello que hacemos en el entendido

\footnotetext{
${ }^{3}$ Spinoza dirá en el prefacio del Tratado teológico-político, cita: "no hay medio más eficaz para gobernar a la masa que la superstición" (TTP, pref. I/30), y tal como lo plantea Capona (2018) en su artículo sobre el papel político de la superstición en Spinoza, el término superstitio en Spinoza que tiene una raigambre latina, tiene un papel teológico-político que se dirige a la dominación de las almas y por tanto se trata de "un dispositivo utilizado por quienes detentan el poder para llevar a los hombres a la sumisión al orden pre-establecido o por establecer." (p. 182). Cabe agregar el carácter fluctuante e inconstante de la superstición entre el miedo y la esperanza.

${ }^{4}$ Recupero el epígrafe que cita Rolnik (2019) del libro de Deleuze y Guattari ¿Qué es la Filosofía?: "El concepto es el contorno, la configuración, la constelación de un acontecimiento por vernir que lo corta y lo recorta a su manera. La grandeza de una filosofía se valora por la naturaleza de los acontecimientos a
} 
spinoziano de aquello que podemos, puesto que "...nadie, hasta ahora, ha determinado lo que puede el cuerpo" (EIII, 2, escolio); generar prácticas capaces de percibir (desaprehender) las tramas afectivas, prácticas que apuesten por la generación de afectos comunes, de experiencias que no renuncian y se resisten al bloqueo de la vida. ¿Cuáles son y cómo se generan estas resistencias?

A partir de la noción de potencia común, analizo dicho entrecruzamiento para pensar un feminismo spinoziano que encuentra en el deseo de vida, en la libertad y la vida afectiva esa potencia común. La libertad y la vida afectiva implican la producción de afectos, de cuerpos políticos que enuncian formas de estar y de resistir. La intención de este artículo es, en un esfuerzo inacabado, pensar de la mano de las luchas feministas esas formas vitales que nos permitan desear deseos comunes y producir afectos colectivos en una apuesta por la vida.

\section{Spinozismo y Feminismo}

El pensamiento de Spinoza, sabemos, suscitó desde sus inicios e incluso antes de que él mismo escribiera algo, enormes controversias y distintas interpretaciones. Recordemos que durante el siglo XVII el estar relacionado con su pensamiento, ser spinozista, significaba ser considerado ateo ${ }^{5}$ y por tanto digno de persecución. Así, el spinozismo va a designar y sintetizar una de las mayores revoluciones en el mundo de las ideas, al articular un conjunto de emancipaciones políticas, religiosas, sexuales y sociales que se extendieron por Europa desde que empezaron a circular sus manuscritos (Tatián, 2012, p. 23). De igual manera, resalta la influencia que tendrá sobre la gente del pueblo, en cuanto filosofía para los no filósofos, un pensamiento cuya comprensión tiende a lo común. De suerte que, desde entonces y hasta nuestros

\footnotetext{
los cuales sus conceptos nos convocan. Ellos son centros de vibraciones, cada uno en sí mismo y unos en relación con otros. Es por eso que todo resuena, en vez de encadenarse o de corresponder unos a otros." (p. 19).

${ }^{5} \mathrm{Al}$ respecto en la nota 37 del texto de Bayle (2010) "Lo verdaderamente imposible en la época no es negar la existencia del Dios de la "religión"; lo verdaderamente imposible, lo impensable, es negar la existencia de un Dios como principio, como causa o incluso como motor del universo. El concepto de "ateísmo" posee, sin duda, como todos los conceptos, una historia. En el siglo XVII no es considerado ateo (...) quien niega la existencia de Dios, sino quien niega la existencia y la efectividad de toda mediación entre Dios y el mundo o los hombres (...) Otra cosa bien distinta -y esto es lo que significa ser ateo en esa época- es la negación de toda libertad, de toda trascendencia, de todo carácter personal predicable de dicho principio" (pp. 23, 24).
} 
días, el pensamiento de Spinoza va a encontrar una recepción profundamente extensa en la producción de ideas e inspirará una diversidad de ámbitos del conocimiento, tanto en las ciencias como en las artes y las humanidades. De dicha producción, como sostendremos aquí, no estará ausente el feminismo, tanto en una visión negativa como positiva de su pensamiento. Cabe mencionar, para efectos de la presente reflexión y para comprender el carácter radical del spinozismo, las lecturas que se derivan del llamado renacimiento de Spinoza del mayo francés en 1968, con autores fundamentales como Deleuze, Gueroult, Matheron y sin duda en la alianza Marx y Spinoza de Althusser, Macherey y Balibar, entre otros; en esa invaluable vuelta a Spinoza se inscriben las lecturas latinoamericanas, tal como lo resume Cecilia Abdo:

Es la irrupción decidida de las filosofías del cuerpo, en las que la acción política se mide por la performatividad, por la posibilidad de ocupación del espacio, en la fugacidad de tiempos múltiples y simultáneos. Qué potencialidades y límites abre la identificación entre acción política y performatividad es la pregunta que arroja el 68 y que todavía resuena, incontestada (Abdo, 2019, p. 19).

Dicho gesto de enunciación y acción, que se abre al espacio de la experiencia política de singularidades situadas, es constitutivo al realismo emancipatorio del spinozismo, entendido como filosofía de la praxis afectiva. No se trata de un pensamiento del naufragio sino de un filósofo en la nave, un pensar en las tormentas y las pasiones humanas en colectivo, así como sus configuraciones políticas (Tatián, 2019, p. 127). Por eso la filosofía de Spinoza será parte de esa corriente subterránea que marcará el horizonte de la inmanencia en la modernidad, tal como lo menciona Morfino (2014), como la corriente que transita invisible en la superficie respecto a la tradición Occidental del logos y el sentido (pp. 9-10) ${ }^{6}$. La propuesta conceptual que trabaja Morfino en torno a la temporalidad plural, la contingencia y la relacionalidad, es fundamental para pensar la potencia de la multitud como un tejido de relaciones, una conexión de trazas y prácticas, un entrecruzamiento de pasiones que atraviesan y

\footnotetext{
6 “La Razón, el Origen, el Fin, la Necesidad, el Orden (el sistema de Leyes que lo establece) no son por lo tanto originarios sino derivados, la filosofía no cierra el círculo del ser reteniendo su sentido (instalándose en el centro), sino que vive en los espacios abiertos, coyunturales, marginales de los encuentros, y no es nada más que la constatación de encuentros que han tomado consistencia" (Morfino, 2014, p.11).
} 
constituyen la sociedad, por lo que hablar de potencia común implica dar cuenta de una compleja trama de relaciones que se actualizan en el encuentro, es decir, "..las pasiones no son propiedad que existen antes del encuentro y se activan por éste, sino que son las relaciones constitutivas del individuo social. Las pasiones no actúan sobre la interioridad, sino sobre el espacio entre los individuos del cual la interioridad misma es un efecto histórico" (Morfino, 2014, pp. 78-79). De ahí que la noción de transindividualidad para comprender la teoría de los afectos de Spinoza sea otro de los aportes conceptuales del spinozismo a la tarea de discernir la condición finita del modo humano, como parte del entramado infinito y eterno de la Naturaleza. Al respecto, Balibar, en su texto De la individualidad a la transindividualidad, recupera el debate en torno a este concepto acuñado por Gilbert Simondon, para analizar la determinación y diferenciación del modo finito que se define por su esencia real como deseo:

La transindividualidad surgirá: primero, como una concepción específica o proyecto de la causalidad (principalmente en las Partes I y II de la Ética); segundo, como la clave para la construcción de sucesivos órdenes de individualidad, u órdenes de integración de individuos más simples dentro de los más complejos (principalmente en la Parte II, con consecuencias encadenadas a través de las Partes III y IV); tercero, como un concepto latente que ( en las Partes III y IV articula imaginación y razón (o, más precisamente, las leyes psicológicas de la imaginación o de la vida imaginaria, derivándose de la ambivalencia básica del deseo humana, y la regla racional de la utilidad recíproca, que crea la posibilidad de comunidades relativamente estables) (Balibar, 2009, pp. 23-24).

$\mathrm{Y}$ dado que nuestro actuar o padecer se encuentra determinado por la capacidad de afectar y ser afectados en un proceso de composición, esto es, de transformación en una continuación indefinida de la existencia, nuestra individuación o autonomía es proporcional a la necesaria relación y utilidad con los otros, dicho de 
otra manera, somos un entramado de tensiones y conflictos, "estamos entretejidos" y

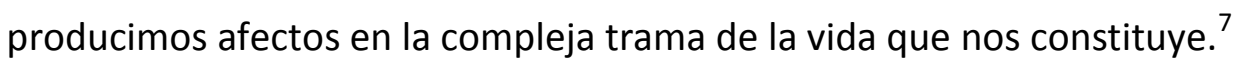

Queda para concluir esta síntesis, para nada exhaustiva, de algunas categorías claves al spinozismo en su propuesta práctica, que éstas se desprenden de la ruptura radical que implica la ontología de lo necesario ${ }^{8}$ de Spinoza frente a la metafísica Occidental, como crítica de la trascendencia divina, el finalismo y el dualismo ${ }^{9}$. De la recuperación y actualización de dicho desafío, pensamos, se comprenderá la necesidad de preguntarnos cómo producir agenciamientos que promuevan la vida en común, en la medida que estamos atravesadas y atravesados por violencias estructurales que capturan nuestros deseos, y puesto que la libertad pasa por la organización y producción de estrategias de vida afectiva y afectos comunes que, como diría Deleuze (2008), efectúan nuestra potencia.

Respecto a los aportes teóricos y prácticos que han dado los feminismos ${ }^{10}$ en su inagotable movimiento social y político, podemos enmarcarlos -considerando las

\footnotetext{
${ }^{7}$ Ver la cita de Lucrecio que comparte Morfino (2014): Inter se mortales mutua vivunt / "Y viven trocándose vida entre sí los mortales" (p. 80)

${ }^{8}$ Al respecto ver el artículo de Marilena, Chaui (2008), donde explica con profunda lucidez la ontología de lo necesario en Spinoza.

9 En mi artículo "Deseo de multitud en Spinoza”, desarrollo estos aspectos de la ontología de la inmanencia y sus derivas éticas y políticas, Oliva (2018, pp. 33-37).

${ }^{10}$ Decimos feminismos en plural y no feminismo, porque en el proceso de construcción y producción teórica y de lucha del (los) feminismo(s), se han desplegado una diversidad de enfoques que enuncian la complejidad del problema, por decirlo enfáticamente, de siglos de invisibilización y negación de las mujeres a lo largo de la historia. Una de las interpretaciones que se ha hecho común para hablar del proceso histórico del feminismo ha sido dividirlo por olas, refiriendo con ello a momentos de fuerte visibilidad de las movilizaciones y la producción teórica, estas olas son: la primera ola que abarca el movimiento ilustrado del siglo XVIII con el paradigma de las vindicaciones feministas, centradas en el reconocimiento de los derechos fundamentales de ciudadanía de las mujeres, la igualdad de derechos y el acceso a la educación, Olympe de Gouges y Mary Wollstonecraft son algunas de las voces representativas de este período; la segunda ola, de la segunda mitad del siglo XIX a principios del XX con el movimiento de las sufragistas que demandaban el sufragio universal, es representativa Seneca Falls, entre otras, junto con la reivindicación del voto están las luchas por la abolición de la esclavitud en Estados Unidos con Sojourner Truth que inaugurará lo que más tarde se denominará "feminismos negros", también en este período se suman los ideales emancipadores de la clase trabajadora y nos encontramos con las socialistas, comunistas y anarquistas que cuestionarán las desigualdades del sistema capitalistas, interpelando, a su vez, la tiranía masculina, se puede mencionar a Aleksandra Kolontái, Flora Tristán, Emma Goldman o el colectivo anarquista Mujeres Libres, en el año de 1949, Simone de Beavoir publica su libro El segundo sexo; la tercera ola de finales de los años 60's, los 70's y hasta el finales del siglo XX en Estados Unidos y Europa donde se desarrolla el feminismo de corte liberal, el feminismo radical, el lesbofeminismo, la reivindicación de los derechos reproductivos, el cuestionamiento del mandato de la maternidad, el carácter sistémico de las violencias contra las mujeres en las sociedades patriarcales, los feminismos de la diferencia; y se plantea que en este siglo XXI
} 
ausencias que para esta reflexión quedan abiertas y que es imposible agotar- en la pregunta por las condiciones de opresión de las mujeres en términos simbólicos, históricos, económicos, políticos y sociales. De dicha pregunta se desprenden varias otras, ¿Cuáles son y han sido las condiciones de dicha opresión? ¿Cuáles son las raíces de la explotación social y económica de las mujeres? ¿Qué derivas y posturas ha significado la lucha por la igualdad de derechos? ¿Qué es ser mujer y cómo ha sido este proceso de naturalización-desnaturalizaicón? ¿Qué significa hablar de reproducción de la vida? ¿Qué ha implicado la ruptura del binomio sexo-género? ¿Cómo han afectado los discursos y las representaciones las vidas de las mujeres? ¿Qué hay del cuerpo y la propiedad? ¿Cuáles son las implicaciones teóricas del feminismo en términos epistemológicos? ¿Qué es el hetero-patriarcado? ¿Cómo ha sido la relación del feminismo y lo común? Podríamos ampliar las preguntas y no alcanzaríamos a enunciar el abanico de problemáticas que el feminismo ha implicado para nuestra construcción de mundo, de historia, de memoria. Sin embargo, podríamos indicar que el movimiento feminista, tanto en términos de producción teórico crítica, como de lucha y experiencia concreta, es un movimiento de emancipación, un movimiento libertario que ha sido inspiración y complicidad con muchos otros movimientos de lucha social y de reclamo de condiciones de vida dignas. En ese sentido, el material conceptual que el feminismo ha producido, podríamos inicialmente sintetizarlo en el "sujeto" del feminismo: las mujeres, en plural porque es plural en sus diferencias teniendo presente el atravesamiento de un sistema patriarcal, heteronormado, capitalista, colonial y racista.

El proceso genealógico de los análisis feministas sobre el "sujeto" del feminismo implicó inicialmente una ruptura con el esencialismo biológico, y la necesidad de pensar el carácter social y culturalmente construido del sexo, puesto que "ser mujer" dirá Beauvoir, en su ya clásica obra El segundo sexo, lo femenino no tiene que ver con la biología sino precisamente con dicha construcción cultural simbólica del sexo; por tanto la condición femenina no pertenece al orden de la Naturaleza, sino al 
proyecto cultural de identidad que han elegido los hombres. De dicho análisis problemático, Judith Butler ahondará y cuestionará el binomio sexo/género, considerando que el sexo es también una construcción cultural. Asimismo, en Francia y en el entramado del movimiento filosófico existencialista, marxista con el psicoanálisis estructural de Lacan, se desarrollará el feminismo de la diferencia, con el importante trabajo de Luce Irigaray, Julia Kristeva, Héléne Cixous entre otras. Irigaray plantea una crítica profunda al falso sujeto universal de la filosofía y el psicoanálisis, que no es ni universal, ni neutro, es la ley que ordena a la sociedad "heteronormada" y "falocéntrica" puesto que se valora y está al servicio exclusivo de las necesidades y deseos masculinos, así los cuerpos de las mujeres se materializan en la medida que sirven al orden masculino, de suerte que en términos del orden simbólico planteado por Lacan, la posición femenina queda fuera de dicho registro. "La subjetividad denegada a la mujer, tal es, sin duda, la hipoteca garante de toda constitución irreductible del objeto: de representación, de discurso, de deseo" (Irigaray, 2017, p.119). La propuesta de Irigaray se centra en el reencuentro e invención de una feminidad simbólica alternativa a la falta, a la envidia del pene ${ }^{11}$ freudiana en la construcción de la identidad femenina. Encontraremos en la feminista Rosi Braidotti una de las derivas del pensamiento de Irigaray, con su concepto de subjetividad nómade. Braidotti (2015) dirá, refiriéndose a Teresa de Lauretis y respecto a la categoría "mujer", que "la pensadora feminista femenina toma como objeto de estudio la experiencia de las mujeres y la categoría de Mujer, y lo hace no sólo para comprender el mecanismo de descalificación de su género, sino también para liberar a la noción de Mujer de la red de semiverdades y prejuicios adonde la confinó el patriarcado" (p. 14). De ahí que la recuperación de la experiencia situada sea central para el proyecto del feminismo, en un sentido político y epistemológico, ya que para el marco conceptual feminista es central el cuerpo, entendido como sitio de intersección de lo biológico, lo social y lo lingüístico, como punto de intersección de la realidad:

\footnotetext{
${ }^{11}$ Al respecto ver la lectura de Millet (1995), quien desarrolla y entiende la opresión patriarcal como política sexual y explica que la psicología freudiana de la mujer, gira en torno a una trágica experiencia original: el haber nacido hembra, que equivaldría a haber venido al mundo castrada; de ahí desarrollará la envidia del pene. (pp. 322-323).
} 
La pregunta feminista femenina es entonces de qué manera afirmar la diferencia sexual no como "el otro", el otro polo de una oposición binaria convenientemente dispuesta para sostener un sistema de poder, sino, en todo caso, como el proceso activo de potenciar la diferencia que la mujer establece en la cultura y en la sociedad. La mujer no es ya diferente de sino diferente para poner en práctica nuevos valores (pp. 16-17).

En esta misma línea crítica, atendiendo a los límites del pensamiento del feminismo de la diferencia y a partir del desarrollo de una línea de trabajo que piensa el género como tecnología, Teresa de Lauretis (1986), señala que la clave crítica está en que el feminismo ha asignado al cuerpo, a lo personal, a lo subjetivo, a lo sintomático y a lo cotidiano, como el sitio en el que lo ideológico se inscribe en la materialidad, esto es, el cuerpo como el terreno en el que las determinaciones sociopolíticas cobran realidad y por tanto, el feminismo no podrá seguir existiendo en ausencia de las diferencias sino con ellas, el sujeto femenino como sitio de las diferencias. Por tanto, dicha subjetividad ha de ser entendida como conciencia política en tensión, es decir, un sujeto constituido no sólo por la diferencia sexual sino como un sujeto en-gendrado en la experiencia de relaciones raciales y de clases, lo que implica pensarlo como un sujeto múltiple y contradictorio. De ahí la importancia que adquiere también, para efectos de la producción conceptual de los feminismos, el análisis de la categoría de "heterosexualidad", desarrollado principalmente por el feminismo lesbiano, tanto el de Adrienne Rich (1996) como el de Monique Wittig (2006); Rich plantea que la heterosexualidad es obligatoria y por tanto, se trata de una institución política impuesta, es decir, un sistema de dominación y de opresión para las mujeres que es tal, por su obligatoriedad social que garantiza un modelo de relación entre los sexos en el que el cuerpo de las mujeres es siempre accesible a los hombres y se traduce en violencia; por su parte Wittig establece que el pensamiento heterosexual es un práctica organizada de relaciones de fuerza, un dispositivo de poder que estructura la opresión social, de ahí que afirma que "las lesbianas no son mujeres", radicalizando su crítica a la categoría y problematizandola en una dialéctica del conflicto. 
Es en este ámbito conceptual de los feminismos de la diferencia y sus derivas materialistas, que feministas contemporáneas elaborarán una lectura del pensamiento de Spinoza en clave feminista ${ }^{12}$ como parte de las propuestas de un feminismo spinoziano. Quedan pendientes, sin embargo, varios conceptos que por espacio y tiempo no puedo desarrollar acá, pero que serán fundamentales para profundizar en la discusión de los entrecruzamientos y composiciones entre el spinozismo y los feminismos, principalmente los elaborados por los feminismos decoloniales, comunitarios, interseccionales, etc; el trabajo de Rita Segato sobre las violencias, Silvia Federici la reproducción de la vida, la acumulación primitiva, lo común, entre y con varias otras, dejando abierta la pregunta ¿a qué afectos nos convocan estos conceptos?

\section{Las mujeres en la democracia spinoziana, el pasaje maldito}

Es abyecto aquello que perturba una identidad, un sistema, un orden. Aquello que no respeta los límites, los lugares, las reglas. La complicidad. Lo ambiguo. La mezcla. Julia Kristeva

En el XIII Coloquio Internacional de Spinoza: Spinoza Maledictus, realizado en Córdoba, Argentina, 2016, nos dimos a la tarea de analizar los pasajes malditos de Spinoza, uno de esos pasajes es el que escribe Spinoza en su inconcluso Tratado Político, en el que expondrá las razones por las que las mujeres han de ser excluidas de la política y no poder ser consideradas sui juris, un pasaje sin duda maldito y "antispinozista" por la contrariedad con la que resuena frente a los fundamentos ontológicos, éticos y políticos de su propuesta filosófica, justo ahí con un gesto de punto final al tema ${ }^{13}$, la pluma se detuvo, ahí en lo que constituiría el despliegue de la potencia democrática de la multitud, cito:

\footnotetext{
12 Una buena parte de estas lecturas se encuentran en el texto compilado por Moira Gatens (2009); también en Vacarezza (2010); Balza (2014); Aguilar (2019); Abdo (2019).

${ }^{13}$ La traducción de Atilano Domínguez del pasaje que citamos, no incluye ese punto final, "Pero nada más sobare este punto", que sí traduce Alfonso Di Severino y que nos parece importante.
} 
Más quizá pregunte alguno si acaso las mujeres están bajo la potestad de los hombres por naturaleza o por ley. Ya que, si ese hecho sólo se fundara en una ley, ninguna razón nos forzaría a excluirlas del gobierno. Ahora bien, basta consultar a la misma experiencia para comprobar que ello se deriva de su debilidad. Pues no ha sucedido en parte alguna que reinaran a la vez los hombres y las mujeres, sino que en cualquier punto de la tierra donde se hallan hombres y mujeres, vemos que los hombres gobiernan y las mujeres son gobernadas, y que, de esta forma, ambos sexos viven en concordia. Por el contrario, las amazonas que, según una conocida tradición, reinaron en otro tiempo, no soportaban que los varones moraran en el suelo patrio, sino que únicamente alimentaban a las hembras, mientras que daban muerte a los machos que habían parido.

Ahora bien, si las mujeres fueran iguales por naturaleza a los varones y poseyeran igual fortaleza de ánimo e igual talento (ingenium) (tal es el mejor índice del poder y por tanto del derecho humano), sin duda que, entre tantas y tan diversas naciones, se encontrarían algunas en que ambos sexos gobernaran por igual, y otras en que los varones fueran gobernados por las mujeres y fueran educados de forma que su poder intelectual fuera menor. Pero, como esto no sucedió en parte alguna, podemos afirmar rotundamente que las mujeres no tienen, por naturaleza, un derecho igual al de los hombres, sino que, por necesidad, son inferiores a ellos. No puede, por tanto, suceder que ambos sexos gobiernen a la par $y$, mucho menos que los varones sean gobernados por las mujeres.

$Y$, si consideramos, además, los afectos humanos, a saber, que los hombre casi siempre aman a las mujeres por el solo afecto sexual y que aprecian su talento y sabiduría en la misma medida en que ellas son hermosas; y que, además, los hombres soportan a duras penas que las mujeres que ellos aman favorezcan de algún modo a otros, y hechos por el estilo, veremos sin mayor dificultad que no puede acontecer, sin gran perjuicio para la paz, que los hombres y las mujeres gobiernen por igual (TP, XI, 4).

El pasaje ha sido leído, principalmente por mujeres desde diferentes percepciones y análisis, que van desde considerar que se trata de la inevitable condición de su época hasta un rechazo total. Recuperaré algunos de esos trabajos, de la mano de nuestra propia interpretación de las implicaciones del texto. Pensar hoy 
que los argumentos que el filósofo holandés expone para excluir a las mujeres del ámbito político sea una mera condición histórica, fruto de su tiempo, y por tanto una expresión más de la "cicatriz" que recorre el pensamiento occidental, resulta ingenuo y diría que impotente para efectos justamente de un análisis del pensamiento de Spinoza desde el feminismo. Me parece que, tal como afirma Vacarezza (2010) y en sincronía con otras autoras, opta por "continuar disfrutando" de la obra del autor por los enormes aportes que hace para pensar el género y sus formas de sociabilidad ético políticas $^{14}$, y que dicha fisura es propia de su tiempo, refleja justamente la necesidad de poner a Spinoza contra sí mismo, porque me parece que una cosa no excluye a la otra, sino que se enriquecen. Desde mi perspectiva se trata de un quiebre, cuyas implicaciones radicales, pensando el realismo político que alberga la propuesta de Spinoza, nos permite someter dicha radicalidad al propio argumento Spinoziano, en tanto pensamiento que se actualiza en las propias fisuras que le constituyen. ¿Por qué Spinoza hace una mención tan específica sobre las mujeres, por qué en la democracia? Y más ¿Por qué en el cuerpo de su pensamiento de la democracia establece distinciones naturalistas e historicistas sobre el papel de las mujeres y la necesidad de mantenerse como alterius juris? específicamente en el Tratado Político.

En el prólogo a la traducción del TP de Alfonso Di Severino, Tatián plantea que las innovaciones más relevantes que contiene el TP se resumen en tres aspectos que no son entre sí independientes, a saber, la ruptura con el contractualismo, la acuñación del concepto de multitud y un maquiavelismo explícito, y presentan

una conexión estrecha para constituir una perspectiva radical-democrática que adopta una posición realista contra el moralismo de los filósofos... La vía seguida por el TP para concebir algo atinente a los asuntos humanos compatible con la experiencia o con la práctica y que pueda ser útil a la sociedad en general toma igual distancia del moralismo de los filósofos y el cinismo de los políticos en favor de una "ciencia de los afectos (pp. 16-17).

Es decir, la necesidad de la política es proporcional a la impotencia de la moral para la regulación de la vida común. Tratando de responder con esto a las preguntas

\footnotetext{
${ }^{14}$ Aguilar (2019), por su parte desarrolla una propuesta de la categoría de las mujeres, a partir de la noción de individualidad de Spinoza.
} 
planteadas, ¿no es moralista y cínico decir que para no perturbar la paz entre los hombres sea necesario que las mujeres no participen del gobierno, contradiciendo la afirmación de que la necesidad de la política es proporcional a la impotencia de la moral? ¿o acaso lo que sostiene la posibilidad de la democracia es mantener la exclusión de las mujeres? En cuanto a la primera pregunta, en la lectura de Matheron (2017) Spinoza desplaza el problema de la exclusión, no a la institución sino a lo natural, y su razonamiento compete al ámbito de la imaginación, elevándose del efecto a la causa. Hay algo en la naturaleza de las mujeres que las pone en desventaja en el juego de las relaciones de poder, que se dan bajo el régimen de la pasión. Hay en ese algo, dirá Matheron, una suposición que destina a las mujeres a la obediencia y a la subordinación: para garantizar la paz del Estado es mejor excluirlas, dado que el amor de los hombre por las mujeres tiene su origen en el apetito sensual y sólo aprecian sus cualidades y su sabiduría cuando son bellas. En dichas condiciones nos encontramos, pues, en el reino de las pasiones, esto es, en el ámbito en el que aún no se establece el común de la razón y por tanto de esa composición colectiva y plural, los límites de la acción política están dados por el derecho de guerra, pero hay un plus de desventaja en esta imagen proyectada de los hombres a las mujeres, o en el hecho de la propia especulación de Spinoza sobre las mujeres. Es decir, Spinoza no escapa a la patriarcalización del género. Dos momentos de la superstición patriarcal, de acuerdo a las estructuras simbólicas y naturalizadas de la mujer, incitación a la lujuria que provocan en los hombres, los cuerpos de las mujeres como propiedad y, su debilidad, que se expresa en la mujeril misericordia en EIVP37, escolio 1, donde habla del bien que apetece para sí lo deseará para los demás hombres, deseo para sí y para los otros... "En su virtud es evidente que leyes como la que prohibiera matar a los animales estarían fundadas más en una vana superstición y en una mujeril misericordia que en la sana razón". La definición de misericordia: "es el amor en cuanto afecta al hombre de tal modo que se goza en el bien de otro y se entristece con su mal", porque las pasiones no son igual en los hombres que en las mujeres, en ellas son condiciones de su naturaleza-histórica y la democracia precisa al menos en la lectura de Matheron, precisa del patriarcado (Abdo Ferez, 2019, p.) 
Retomando, la segunda pregunta, comparto totalmente la lectura de Abdo Ferez, (2018) al plantear que la alusión a la paz desmiente el argumento de la naturaleza para fundamentar la división sexual, parece entonces que la división sexual y la sujeción de un sexo-género respecto de otro es sugerido como: un régimen político de producción de esa división, y más aún se lee que hay ciertas asunciones de identidades colectivas que no suman a la concordia y a la vida de la comunidad, porque socavan el suelo de la dominación que sostiene dicha concordia (pp. 68-71); es decir que mantener la seguridad del Estado pasa por el sometimiento de las mujeres y la necesidad de preservar la subordinación a los hombres, permanecer alterius juris, para el sostén del sui juris.

Las huellas de este texto, hacen agua por todos lados la propuesta filosófica de Spinoza, la dinamita, siguiendo a Abdo Ferez, la identificación entre naturaleza e historicidad para justificar una posición subordinada, la referencia a las naciones, como dispositivo lingüístico de producción de una división sexual, heteronormada y asumida como natural, y la alusión a la paz que permitiría mantener esa división sexual como condición necesaria de una institucionalidad democrática. Insalvable Spinoza.

Pero, la pregunta es ¿Resulta insalvable Spinoza para el feminismo? La respuesta me parece que está justamente en las propuestas de un feminismo spinoziano, concretamente en la apuesta por la potencia común de los cuerpos colectivos, por la producción de cuerpos disidentes, de ello hablaré en lo que sigue.

\section{Feminismo spinoziano: libertad y vida afectiva como potencia común}

Mi geografía más cercana. Empiezo, no por un continente, un país o una casa, sino por la geografía más cercana: el cuerpo. Aquí al menos sé existo, que soy ese individuo humano viviente al que el joven Marx denominó "la primera premisa de toda la historia humana". Pero no he acudido a este lugar como marxista de vuelta de la filosofía, la literatura, la ciencia y la teología en las que me había estado buscando a mí misma en vano. He venido como feminista radical. No para trascender este cuerpo, sino para reclamarlo. Adrienne Rich 
En el resumen/abstract del presente artículo, me preguntaba si el feminismo necesita del pensamiento de Spinoza o digamos del spinozismo, mi respuesta es que se trata de una mutua necesidad, respondiendo a la pregunta de si es salvable Spinoza para el feminismo, diría que Spinoza se salva por el feminismo. Abdo Ferez plantea que “Spinoza precisa ser leído, spinocistamente, contra sí mismo" (p. 74), coincido y propongo que precisa ser leído desde un feminismo spinoziano, ese contra sí mismo intensifica su crítica desde la perspectiva del feminismo, es decir, como sí las estrategias conceptuales del spinozismo, utilizadas desde los caminos de resistencia conceptual y práctica de la lucha feminista adquiriesen una mayor realidad, una mayor perfección. Me explico, en un diálogo ya establecido con la reflexión al pasaje del TP, XI, 4 con Abdo Ferez (2019), ella plantea que los feminismos contemporáneos hemos venido abrevando en su pensamiento, precisamente respecto a su concepción del cuerpo colectivo, para habilitar y pensar al cuerpo como materia productiva y barroca, dado que, Spinoza afirma que los cuerpos son, constitutivamente, un haz de relaciones afectivas, un historial de encuentros con otros cuerpos, que lo regenera continuamente, recreando su potencia de hacer y pensar (p. 74) y a la respuesta de cómo Spinoza, muestra su revés frente a la no problematización de las causas de esa subordinación, en tanto causa adecuada, dirá que "Spinoza muestra el revés de la trama y un plan de acción posible para las mujeres: una forma de vida política de insubordinación. Un emanciparse del estado de alterius juris, que impactará en quienes están habilitados a ser sui juris en el espacio público..." (p. 75); así en un genuino desiderium, anhelo de venganza, como motor de un deseo de justicia, de acuerdo al análisis que expone de Jaquet, tal como sucede con los afectos de la resistencia y la indignación, que trabaja Bove (2014), no hay resignación, ni victimismo, esto es, "dejar de ser excusas para el incremento de políticas de seguridad represivas" (p.76).

Desde esta propuesta, sostengo un feminismo spinoziano que se implica en la libertad y vida afectiva entendida como potencia común. Considerando que la verdad en el sistema de pensamiento de Spinoza se inscribe en alcanzar la virtud, esto es la felicidad y la libertad, como el mayor de los deseos por los que ha de esforzarse el 
alma humana y que dicha práctica se constituye como el ejercicio afectivo de la vida a través de la cual expresamos nuestra potencia de existir y nuestra capacidad de afección, pensarla desde la radicalidad crítica de los feminismos, significa pensar la sabiduría de la vida misma sin eludir el trasfondo afectivo que todo acto de entendimiento implica.

Por eso la potencia feminista es potencia del cuerpo como cuerpo siempre individual y colectivo y en variación, es decir, singularizado. Pero además la potencia feminista expande el cuerpo gracias a los modos en que es reinventado por las luchas de mujeres, por las luchas feministas y las luchas de las disidencias sexuales, que actualizan la potencia, reescribiendo a Spinoza y a Marx (Gago, 2019, p. 10).

Reescribir a Spinoza desde la lucha feminista implica, recuperar e inventar prácticas de vida común y eso supone comprender el sentido que tiene no sólo al interior de la Ética la frase "nadie sabe lo que puede un cuerpo", sino su implicación para pensarnos políticamente, esto es pensar las relaciones de poder que producimos, sus discursos, sus prácticas y sus formas de disciplinamiento, desde el entramado que constituye nuestra condición material, deseante, de ahí la idea de pensar con Spinoza el hecho de devenir cuerpos y preguntarnos con ello cómo hacernos cuerpos políticosdisidentes.

La relación libertad y vida afectiva, implica pensar necesariamente a Spinoza como dispositivo crítico de modos de hacer y producir disidencias, ¿̇y qué significa producir disidencias? Significa, dirá Tatián (2019) pensar y sentir nuestra experiencia colectiva que abraza nuestra condición finita, esa paradójica condición de sabernos soledades y a su vez sabernos en y con otros, otras, otroas, otroes, denunciando así todas las formas de tristeza que disminuyen la potencia de actuar. El gesto ético y político es no someter las disidencias a la condena, sino a la apertura al deseo de otros y esto solo sucede cuando somos capaces del encuentro de nuestra singularidad en lo común, esa vuelta a la composición de afectos alegres que renuncian a la censura, que apelan a la intervención, a la generosidad, a una política de los afectos, de las coyunturas, de los vínculos y a esa incierta composición de afectos alegres, de intuiciones que se cuidan y acompañan en una especie de eternidad. 
Puesto a la luz de las disidencias que ponen en común las luchas feministas, es hacer visible la producción de afectos, en tanto cuerpos-territorios, y pensar formas de vida afectiva que apuestan por la vida y contra las violencias estructurales de un sistema patriarcal, capitalista, colonial y racista, entonces ¿qué afectos? y ¿cómo producir afectos que aumenten nuestra potencia en medio de las violencias estructurales? ¿Cuál es el signo, el vestigio, la huella en la alteridad infinita? En eso “impersonal” -que como señala Isabel Balza (2014) es político-, en la afirmación de la diferencia y la singularidad del deseo, en el desplazamiento y descentramiento del sujeto, pensamos desde el spinozismo el cuerpo como "locus de una potencia singular". ¿El cuerpo, entonces, no como identidad sino como espacio de composición de disidencias? Si los cuerpos son campos de inscripción del poder, ¿qué modela en ellos las posibilidades de pensamiento, derecho y acción de acuerdo a marcos socialmente dispuestos, moralmente connotados, valorativamente jerarquizados (Abdo, 2017)? ¿Qué significa pensar el deseo, la memoria, la resistencia de ese cuerpo político que enmarca la lucha de las mujeres, en ese abrirse a la huella, al reenvío del ¡Vivas nos queremos!, un reenvío que afirma la Vida?

No hay cuerpo sin memoria, la huella tiene en Spinoza la presencia inmanente de una cosa ausente, la afección de la esencia es entonces la esencia de todas las relaciones y de su potencia. Hay un potencial político en el cuerpo común de las mujeres, cuya enunciación es hoy condición estratégica de ese deseo de lo común, de ese deseo de producir nuevos afectos/afecciones que no sucumban a la tristeza, de esa temporalidad común y plural que acompaña la reproducción de la vida.

Mientras no desmontemos el cimiento patriarcal (capitalista-colonial) que funda las desigualdades y expropiaciones de valor que construyen el edificio de todos los poderes (...) mientras no causemos una grieta definitiva en el cristal duro que ha estabilizado desde el principio de los tiempos la prehistoria patriarcal de la humanidad, ningún cambio relevante en la estructura de la sociedad parece ser posible (Segato, 2016, p. 19-20). 
En este sentido, me convenzo de que producir otros afectos, otras formas de gestión de la vida afectiva, otras imágenes, otra escucha, otra afirmación de la vida común desde las luchas feministas, y entonces, pensar un feminismo spinoziano, no sólo es posible sino necesario.

Los afectos son variaciones de la potencia, de la potencia de actuar del cuerpo y del alma simultáneamente. Se trata de la experiencia de un pasaje, de una variación, por lo que se trata de inventar estrategias que fomenten encuentros que aumenten nuestra potencia. Puesto que no se puede saber qué es lo que puede un cuerpo antes de la experiencia, se trata de una disposición afectiva a preparar, entrenar el cuerpo/mente, donde hay algo de riesgo. Spinoza dice en EIIP59, respecto a la actualización del deseo a través de los afectos referidos al actuar y al entendimiento, que “...mientras disfrutamos de la cosa que apetecemos, el cuerpo adquiere en virtud de ese disfrute una nueva constitución por la cual es determinado de otro modo que lo estaba y se excitan en él otras imágenes de las cosas...". Como lo expresa Abdo, Ferez (2019), se trata de lograr las condiciones para que cada cual pueda explorar su deseo, desear que cada quien pueda desear, en el sentido de hacer, pensar, ser (p.95), qué resistencias, qué acuerpamientos, qué luchas, qué encuentros. ¿Qué mediaciones se ponen en juego en la denuncia de la opresión y en la renovación de la trama afectiva?

En medio de todas estas preguntas, los afectos y deseos que he sentipensado a partir de diversas experiencias son los siguientes:

- Deseo común de Vida

- "Deseo de cambiarlo todo"

- Desobedecer

- Reconfiguración del miedo y la esperanza, hacia otros registros de enunciación y práctica.

- Radicalizar la ternura

- Cuerpos-territorio / paisajes formas de vida y que sostienen y defienden la vida

- Vulnerabilidad política

- Ferocidad

- Elaboración de las diferencias del duelo a la lucha política colectiva 
- Deseo de comunalidad

- Procesos de desidentificación

- Acuerpamiento / acompañamiento / escuchas que fortalecen la autonomía

- Inteligibilidad de la violencia estructural y su reproducción en nuestras cuerpas

- Escucha / proximidad / respiración colectiva un común ritmo / marchas

- Creatividad en la resonancia

- Cuidado / pedagogía del cuidado

- La necesidad del vínculo

A la manera de un cierre provisorio de esta reflexión inacabada: vale la pena experimentar la libertad y la vida afectiva, su trama sutil y profunda, acompañando la voz zapatista que nos dice que hay que "organizar la rabia y defender la alegría." 
Referencias bibliográficas:

(2000), Feminismo y Filosofía, Madrid: Síntesis.

Abdo Ferez, C. (2017). ¿Qué puede un cuerpo? Los límites de Spinoza. En Armando Villegas, Natalia Talavera, Roberto Monroy y Laskmi de Mora (Eds.), Fiaras del discurso II. Temas contemporáneos de política y exclusión (pp. 89103). Cuernavaca, México: UAEM-Bonilla Artigas.

Abdo Ferez, C. (2018), Gobernar a las mujeres, la proposición XI, 4 del Tratado Político de Spinoza o los problemas de la relación naturaleza e historia. En Ana Leila Jabase, Carmela las Heras Pronello, Alejandra Meriles, Francisco Rivera (Comps.), Treceavo Coloquio Spinoza Maledictus, (pp. 59-70). Córdoba: Edición Digital PDF.

Abdo Ferez, C. (2019). Contra las mujeres (in)justicia en Spinoza, Madrid: Antígona.

Aguilar, C. (2019), Mujeres: Resignificación, resistencia y alianzas. Una propuesta desde la teoría de la individualidad spinoziana. Buenos Aires: Ragif.

Amorós, Celia. (1985), Hacia una crítica de la razón patriarcal, Madrid: Anthropos.

Balibar, E. (2009). De la individualidad a la transindividualidad, (Anselmo Torres, Trad.). Córdoba: Brujas.

Balza, I. (2014). Los feminismos de Spinoza: corporalidad y renaturalización. Daimon. Revista Internacional de Filosofía, no. 63, pp. 13-26.

Bayle, P. (2010). Escritos sobre Spinoza y el Spinozismo, (Pedro Lomba, Trad.). Madrid: Trotta.

Beltrán, E; Maquieira, D; Álvarez, S; Sánchez, C, (2008), Feminismos. Debates teóricos contemporáneos. Madrid: Alianza.

Bove, L. (2014). La estrategia del conatus. Afirmación y resistencia en Spinoza, (Gemma Sanz Espinar, Trad.). Buenos Aires: Cruce.

Braidotti, R. (2015). Feminismo, diferencia sexual y subjetividad nómade, (Amalia Fischer Pfeiffer, Ed.). Barcelona: Gedisa.

Capona, D. (2018). El papel político de la superstición y el deseo en Spinoza. Consideraciones actuales sobre el capitalismo. Ideas y valores 67.168 (2018), 177-197.

Chaui, M. (2008). O fim da metafísica: Espinosa e a ontología do necessário. En D. Tatián (Comp.), Spinoza. Cuarto coloquio (pp. 11-38). Córdoba: Brujas.

De Lauretis, T. (1986). Estudios Feministas. Estudios críticos: Problemas, conceptos y contextos. En Ramos. C. (Comp.). El Género en perspectiva: de la dominación universal a la representación múltiple, (pp. 165-193). México: UAM Iztapalapa. 
Deleuze, G. (2008), En medio de Spinoza, (Equipo editorial Cactus, Trad.). Buenos Aires: Cactus.

Gago, V. (2019). La potencia feminista o el deseo de cambiarlo todo. Buenos Aires: Tinta Limón.

Gargallo, F. (2012), Feminismos desde Abya Yala. Ideas y proposiciones de las mujeres de 607 pueblos en nuestra América, Bogotá: Desde abajo.

Gatens, M. (Ed.), (2009), Feminist interpretations of Benedict Spinoza, USA: Pennsylvania State University Press.

Irigaray, L. (2007). Espéculo de la otra Mujer, (Raúl Sánchez Cedillo, Trad.). Madrid: Akal.

Marcos, S. (2013). Mujeres, indígenas, rebeldes, zapatistas, Chiapas: Unitierra. Matheron, A. (2017). Mujeres y servidores en la democracia spinozista, (Sergio Rojas Peralta, Trad.). Anacronismo e Irrupción. Revista de Teoría Política Clásica y Moderna. 7/12, 160-181.

Mbembe, A. (2020). La pandemia democratiza el poder de matar, lavoragine.net Millet, K. (1995), Política sexual, (Ana María Bravo García, Trad.). Madrid: Cátedra.

Morfino, V. (2014). El tiempo de la multitud, (Roberto Peña León, Mariana Gaínza, Sebastián Torres, Trads.). Madrid: Tierradenadie.

Oliva Ríos, M. (2018). Deseo de multitud en Spinoza: estrategias críticas de lo común. En J. Ezcurdia (Coord.)., Cuerpo, resistencia y producción de subjetividades frente a la lógica de la globalización capitalista (pp. 29-58). México: Universidad Nacional Autónoma de México, Facultad de Filosofía y Letras.

Ranea Triviño, B. (2019), Feminismos. Antología de textos feministas para uso de las generaciones más jóvenes y las que no lo son tanto, Madrid: Los libros de la Catarata.

Rich, A. (1996). Heterosexualidad obligatoria y existencia lesbiana (1980). Douda Revista dÉstudis Feministes, 10, pp. 15-42.

Rolnik, S. (2019). Esferas de la insurrección, (Cecilia Palmeiro, Marcia Cabrera, Damían Kraus, Trads.). Buenos Aires: Tinta Limón.

Segato, R. (2016). La guerra contra las mujeres. Madrid: Traficantes de Sueños.

Spinoza, B. (2007). Ética demostrada según el orden geométrico, (Vidal Peña García, Trad.). Madrid: Alianza.

Spinoza, B. (2008). Tratado teológico político, (Atilano Domínguez, Trad.). Madrid: Alianza.

Spinoza, B. (2014). Tratado Político, (Alfonso Di Severino, Trad.). Buenos Aires: Quadrata.

Tatián, D. (2012). Spinoza, el don de la filosofía, Buenos Aires: Colihue. 
Tatián, D. (2019). Spinoza disidente, Buenos Aires: Tinta Limón.

Vacarezza, N. (2010). Aportes de Spinoza para reflexionar acerca de la vida corporal del género, las mujeres y el feminismo. A Parte Rei, 71, septiembre, pp. 1-10.

Wittig, M. (2006), El pensamiento heterosexual y otros ensayos, (Javier Sáez y Paco Vidarte, Trads.). Madrid: Egales.

Zuleta, E. (2017), Elogio de la dificultad y otros ensayos. Bogotá: Biblioteca Nacional de Colombia. 